\title{
OS PROJETOS DE COLONIZAÇÃO E COMÉRCIO TOSCANOS NO BRASIL AO TEMPO DO GRÃO DUQUE FERNANDO I (1587-1609)
}

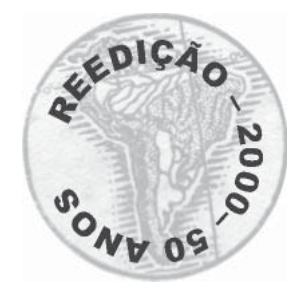

Sérgio Buarque de Holanda

\section{Res U M 0}

$\mathrm{O}$ artigo examina, com base em documentação inédita reproduzida em anexo, as atividades comerciais e os projetos de colonização na América portuguesa empreendidos por Fernando I da Toscana no final do século XVI e início do XVII; bem como examina a política marítima de Florença antes de sua transformação em Principado.

\section{Abstract}

Based on unpublished sources (reproduced at the end of the text) this article examines the comercial activities and the colonization projects in Portuguese America accomplished by Ferdinand I Duke of Toscana at the end of the XVIth and beggining of the XVIIth centuries. It examines also Florence's overseas policies before it became a Principate.

\section{Palavias - Chave}

Florença - América ibérica - Comércio e colonização - Séculos XVI e XVII.

\section{Keywords}

Florence - Iberian America - Trade and colonization $-\mathrm{XVI}^{\text {th }}$ and $\mathrm{XVII}^{\text {th }}$ centuries.

\footnotetext{
* Este artigo foi publicado originariamente na Revista de História $\mathrm{n}^{\circ} 71,1967$, com a seguinte qualificação do autor: Professor de História da Civilização Brasileira da FFCL/USP. O texto foi modernizado em sua ortografia e sua Bibliografia padronizada de acordo com as Normas da Revista.
} 
m um dos capítulos mais provocadores de sua obra mestra, onde expõe como os altos e baixos nas relações entre o mundo mediterrâneo e o espaço atlântico iriam resolver-se, no curso do século XVI, em favor dos povos do Norte, aludiu Fernand Braudel, de passagem, às tentativas "bem curiosas do Grão-Duque Fernando de Toscana, de acordo com os holandeses, para alcançar o Brasil e as Índias Orientais..." (Braudel 1949: 167)

A oportunidade que me ofereceu uma estada de dois anos na Itália, de entrar em contato direto com arquivos florentinos a contar de 1952, permitiu-me recolher alguns textos que poderiam esclarecer as tentativas mencionadas por Braudel, merecedoras, sem dúvida, da atenção dos nossos estudiosos e professores de História. Os documentos que passarei a reproduzir, em sua maior parte inéditos, representam antes de tudo uma contribuição para quem pretenda realizar trabalho mais largo. Ou melhor, nas palavras que me escreveu, em carta de 5 de dezembro de 1953, o então diretor do Arquivo de Estado de Florença, têm eles um valor "apenas indicativo para ulterior extensão das pesquisas a outras filze onde também se acharão certamente notícias sobre o Brasil". As exigências de trabalho constante que me prendiam à Universidade de Roma, impediram-me então de ampliar muito mais as investigações iniciadas no arquivo mediceo.

Em livro publicado há oito anos tive ocasião de tocar, também passageiramente, no interesse devotado a coisas brasileiras pelo grão-duque Fernando I, e em particular em um seu curioso plano de mandar colonos toscanos ao Brasil ou, com mais precisão, à capitania do Espírito Santo, onde sonhara mesmo estabelecer um feudo em favor do segundo ou terceiro filho, no intuito confessado de prevenir possíveis lutas dinásticas depois de sua morte. Procurei, no mesmo livro, relacionar esse projeto do grão-duque com as novas que se faziam quentes no sertão da antiga capitania de Vasco Fernandes Coutinho sobre a existência ali de minas preciosas.

\footnotetext{
* Nota do Editor: trata-se de Visão do Paraíso. Os motivos edênicos no descobrimento e coloniza-
} ção do Brasil, 1959. 
Dos tratos com holandeses a que se refere Braudel não cheguei a achar sinal nos arquivos florentinos, mas é provável que investigação mais acurada permita esclarece-los. Sabe-se, contudo, de certa proposta feita em 1608 ao grão-duque de Toscana por um "humílimo servo de Sua Alteza Sereníssima”, no sentido de valerse ela dos préstimos dos armadores de Amsterdã para o comércio com as Índias Orientais e o Brasil, impressa por Galuzzi (1781) em sua história do grão-ducado sob o govêrno dos Medici. Só muito recentemente vim, aliás, a conhecer a obra básica de Galuzzi, graças a Engel Sluiter, que não só me chamou a atenção para esse e outros passos importantes do historiador toscano, quando em 1965 o visitei em Berkeley Califórnia, como deles, e também dos Cenni Istorici de Gustavo Uzielli (1901), me forneceu as reproduções em xerox utilizadas para estas notas.

Segundo essa proposta que não vem, aliás, assinada, seria dispensável ao grãoduque adquirir as embarcações necessárias para o tráfico ultramarino, bastando-lhe fretar na Holanda navios semelhantes aos que têm carta de frete para a Oostlândia, isto é, o Báltico, muitos deles capazes de carregar grandes quantidades de açúcar (ao menos 6.200 cantari cada qual) e numerosos quintais de pau-brasil, que se acomodaria no meio da estiva das caixas onde o açúcar é acondicionado. Levariam os navios uma sobrecarga de mercadorias que se destinassem às Canárias, e em troca dessas mercadorias, transportadas a Tenerife ou Las Palmas, carregariam nas mesmas Canárias 200 a 300 pipas de vinhos, "che é la miglior mercanzia per il detto Brasile", ao passo que da Holanda iriam panos, telas, e outros artigos que é uso venderem-se naquelas partes, e de tudo resultaria muito bom negócio a Sua Alteza Sereníssima (Galuzzi 1781: 123-5). Não ficaria aqui o negócio, pois descarregados em Liorne, receberiam os navios alume, sal, arroz e mais produtos, conforme a procura que tivessem, para vender aos portos do Poente, e assim também melaços.

Para terminar lembra o correspondente anônimo que, se assim aprouvesse a S. A. S., bem se poderia fazer na própria Amsterdã o seguro, parcial ou total, das mercadorias levadas nessas viagens entre a Holanda e o Brasil e entre o Brasil e Liorne, com todas as escalas necessárias, à taxa usual, que era de 28\%. Mais não seria preciso para interessar no projetado negócio os capitalistas neerlandeses, de longa data es- 
pecializados nos seguros marítimos, dispondo mesmo de uma Câmara onde se registravam os contratos e se dirimiam as dúvidas eventualmente suscitadas. Somandose a isso a fretagem dos navios, outra especialidade dêsses capitalistas, pode-se imaginar a participação eminente que teriam eles na nova política econômica inaugurada por Fernando I. Não só depois, mas já antes da trégua de 1609, segundo uma autoridade na matéria, grandes mercadores e até burgomestres de Amsterdã tinham o hábito de fornecer embarcações a súditos do rei de Espanha residentes nos Países Baixos do sul, e até ao próprio rei. "No primeiro quartel do século XVII", acrescenta Violet Barbour, "Veneza freta barcos holandeses, e a Toscana adquire do almirantado amsterdamês o grande De Hollandsche Tuyn com seus quatro mastros". "A companhia inglesa de Moscóvia fretou navios, também em Amsterdã, entre 1597 e 1598. Pela mesma época, firmas lusitanas do Pôrto fretaram igualmente embarcações holandesas para o comércio do Brasil" (Barbour 1963: 31-3). E são esses apenas uns poucos exemplos, entre inúmeros semelhantes, que se assinalam até bem entrado o século XVIII.

Nova e considerável contribuição para o estudo das atividades comerciais e dos projetos colonizadores de Fernando I da Toscana, particularmente no que respeita ao Brasil, aparece em recente publicação de Roberto Ridolfi (1962: 705-720). Valendo-se de documentos colhidos em arquivos florentinos, dois dos quais vão a seguir reproduzidos - o $7^{\circ}$ e o $9^{\circ},-$ assim como de textos já publicados, o erudito biógrafo de Maquiavel, Savonarola e Guicciardini, se ainda não esgota e nem pretenda esgotar seu tema, ajudará a melhor alinhavar os dados de que já dispomos acerca daquelas atividades.

No que toca ao Brasil, uma das informações mais interessantes que traz esse estudo prende-se à expedição, geralmente ignorada de nossos historiadores, que sob o comando do capitão inglês Thornton, se dirigiu em setembro ou outubro de 1608 ao rio Amazonas. Formada de um galeonete, o Santa Lúcia Bonaventura e de uma tartana não nomeada, armara-a secretamente Fernando I, incumbindo de organizála Sir Rober Dudley, conde de Warwick, estabelecido agora na Toscana. Além de escolher para capitanear a galeoneta e comandar a expedição seu compatriota Thornton, Dudley fornecera a este minuciosas notícias que teria recolhido ele próprio 
durante os bons tempos da rainha de Inglaterra, quando navegou por aquelas partes, um pequeno vocabulário de palavras de uso corrente entre os indígenas do lugar, e cartas náuticas da costa norte do Brasil, que igualmente preparara. Dos dois barcos só o galeonete pôde cumprir integralmentc a missão - pois a tartana, impelida por uma tormenta, teve de refugiar-se no porto de Cartagena, onde a retiveram as autoridades espanholas - e foi, sustenta-o Ridolfi, "talvez o primeiro navio a subir muitas milhas, contra a corrente, o rio das Amazonas". Apenas, quando chegou de volta a Liorne, a 10 de julho de 1609, já não pertencia aos vivos Fernando I, o patrocinador secreto da expedição. A safra de tamanhos trabalhos e despesas deve ter parecido pobre: macacos, papagaios, algum indígena, além de muitas noticias que a Dudley servirão mais tarde para compor seu Arcano do Mar.

$\mathrm{Na}$ literatura histórica brasileira a única referência de que tenho lembrança à viagem de Thornton, é uma lacônica alusão do barão do Rio Branco na $1{ }^{\text {a }}$ Memória sobre a questão de limites com a Guiana Francesa. Depois de mencionar as expedições de ingleses ao Oiapoque e ao Baixo Araguarí, onde aparecem os nomes de Charles Leigh, Robert Harcourt, Edward Harvey e Michael Harcourt, ajunta apenas que de 1608 a 1609 houve outra exploração das costas da Guiana realizada pelo capitão Robert Thomton. Não é provável que tivesse tomado a informação ao Arcano do Mar, embora cite essa obra várias vezes, como a cita Joaquim Caetano da Silva, senão deveria registrar corretamente o local das explorações: rio Amazonas, não costa da Guiana. É estranhável, por outro lado, que a dois autores tão meticulosos como Joaquim Caetano e Rio Branco, conhecedores, ambos, do Arcano, escapasse a relação que nele se dá da viagem de Thornton, ao ponto de parecer ignorá-la o primeiro e de enganar-se, o outro, sobre a região visitada.

Não me foi possível consultar o magnum opus de Dudley e nem as duas outras fontes impressas de maior importância para o histórico da expedição, faltando-me assim elementos para opinar melhor sobre o assunto. Essas duas fontes seriam o livro de G. Temple Leader, Roberto Dudley, duca di Nortumbria, Florença, 1896 e o de G. G. Guarnieri, Un'audace impresa marittima di Ferdinando I, ganduca di Toscana, etc., Pisa, 1928. Em um e outro insere-se breve relato da viagem de Thornton 
compilado por Dudley, e que os dois, escreve Ridolfi, tinham extraído (... entrambi I'avevano ricavato...) do Arcano del Mare (Florença, 1661, II: 33 - $2^{\mathrm{a}}$ impressão) do mesmo Dudley, e, no de Guarnieri, além de outros documentos de alto interesse, as instruções náuticas fornecidas por Sir Robert ao capitão Thornton, antes da partida. Fica a dúvida para quem melhor do que eu possa resolvê-la.

A dúvida é em parte sugerida por aquela referência de Rio Branco à "exploração da costa da Guiana", em lugar do rio Amazonas, e pelo silêncio de Joaquim Caetano da Silva, acerca de uma suposta exploração do rio mar, embora pudessem esses autores encontrar eventualmente dados mais precisos na "breve relação" impressa no Arcano del Mare, que consultaram e citaram, ao menos o segundo, na mesma impressão de 1661 a que se reporta Ridolfi. Além das obras impressas em que se funda, baseia-se o historiador florentino para suas conclusões, em documento do Arquivo de Estado de Florença: uma carta do próprio grão-duque, datada de dezembro de 1608, ao seu embaixador junto à Côrte de S. M. Católica, onde, mencionando a expedição, que atribui à iniciativa de "alguns mercadores residentes em Liorne", dá-lhe expressamente como fito o "Rio dell'Amazzone". Redigida a carta, quando ainda era cedo para se saberem os frutos da viagem, restaria perguntar se, sendo tal a intenção de Fernando I ou daqueles mercadores, foi ela corroborada pelos resultados alcançados. Ao que só o exame das outras fontes poderia talvez responder.

Além disso declara ainda Ridolfi que as instruções dadas por Dudley a Thornton, assim como o vocabolarietto indígena e as cartas náuticas das costas brasileiras, foram organizadas com elementos que o próprio conde de Warwick levou de uma viagem àquelas partes. Ora a única viagem de Dudley à América do Sul fôra, ao que se sabe, a que realizou entre 1594 e 1595, da qual deixou relato que posteriormente imprimiu Richard Hakluyt. Tendo partido rumo a Trinidad e à costa do Paria, sabe-se, pelas suas mesmas informações, que explorou o litoral até ao Oiapoque, por conseguinte a Guiana, antes de voltar à Inglaterra através do Porto Rico e das Bermudas. Em nenhum lugar deixa entender que visitou o rio Amazonas. Na relação que redigiu a pedido de Hakluyt, a mesma que foi por este impressa, consta um pequeno vocabulário de 17 palavras da língua dos 
indígenas de Trinidad ${ }^{1}$, e bem poderia ser aquele vocabolarietto que forneceu depois a Thornton. Assim também as cartas náuticas que entregou a este, pela mesma ocasião, baseadas na experiência própria, deveriam ser as da costa visitada em 1594-1595.

Por outro lado, as cartas geográficas reproduzidas no trabalho de Roberto Ridolfi da edição de 1661 do Arcano, e que em parte já tinham figurado na impressão anterior desse tratado cosmográfico, a de 1647, deixam sofrivelmente debuxadas a boca e parte do curso do "Amazone ò Orellana", e também de um de seus afluentes, que só pode ser o Tocantins. Se as notícias levadas por Thornton da viagem do Santa Lúcia Bonaventura foram utilizadas por Dudley na composição de seus mapas, não está excluída a possibilidade do galeonete ter atingido, como o presume Ridolfi, parte apreciável da costa hoje brasileira, embora elementos aproveitados nos mapas pudessem provir de outras fontes, já que alguns topônimos neles registrados são certamente posteriores a 1609 .

Para a melhor inteligência dos projetos de Fernando I acerca do comércio e colonização de terras brasileiras, seria mister acenar para as origens da expansão territorial e da política marítima de Florença, que antecedem de longe à criação do Principado e mesmo à ascensão de Cosme de Medici, o Velho, pois deita raízes na conquista de Pisa, que data de 1406, e depois na ocupação do Porto Pisano, que, junto à boca do Arno, estava bem situado para transformar-se no escoadouro natural da Toscana. Livorno, na vizinhança imediata de Porto Pisano, fôra uma fortaleza - até 1451 em poder dos genoveses -, que de início não permitia o fácil acesso a embarcações de maior calado.

\footnotetext{
1 "A voyage of the Honourable Gentleman Mr. Robert Dudley, now knight, to the isle of Trinnidad, and the coast of Paria; with his returne home by the Isles of Granata, Santa Cruz, Sant Juan de puerto rico, Mona, Zacheo, the shoalds called Abreojos, and the isle of Bermuda. Written at the request of M. Richard Hakluyt”. Richard Hakluyt, The Principal Navigations Voyages Traffiques \& Discoveries of the English Nation, vol. $7^{\circ}$, Londres e Toronto, J. M. Dent and Sons Lted, e Nova York, E. P. Dutton \& Co., 1927: 164-172.
} 
A construção ali do porto e mesmo a fundação da cidade de Liorne para substituir precisamente o Porto Pisano, bloqueado pelos bancos de areia e, assim, inutilizado, desde 1540 se não antes, - iniciara-se antes do advento de Fernando I, embora seu grande progresso só começasse realmente com ele, depois de 1587 (Roover 1966: 275). A esse ambicioso neto de Giovanni dalle Bande Nere cumpre igualmente associar o desenvolvimento da frota de guerra toscana, que já em 1608 e 1609 se imporá ao próprio turco, com as vitórias de Bona e do Arquipélago.

Num florentino e num Médici não é de admirar que ao gosto das aventuras bélicas se casasse admiravelmente o pendor para empresas mercantis. A captura de áreas em poder ou ao alcance dos otomanos, em particular a da ilha de Chipre, tentada já em 1607, prometia gastos e riscos talvez menos compatíveis com as possibilidades do incipiente poderio toscano. Outro projeto que o grão-duque chegara a acariciar, o de obter para um filho seu certas terras feudatárias da Coroa de Nápoles, iria chocar-se quase inevitavelmente com as insolências dos vice-reis. Entende-se, pois, como à sua imaginação devesse parecer um campo mais desembaraçado o remoto Brasil.

Não será alheia, talvez, aos seus planos políticos e econômicos, nesse particular, uma ocorrência quase contemporânea de sua ascensão ao poder. Menos de cinco meses antes de subir ele ao trono, em março de 1588, fôra nomeado para governar o Brasil, Francisco Giraldes, donatário da Capitania de Ilhéus, adquirida por Lucas, seu pai, com licença do rei, aos herdeiros do primeiro donatário, e foi o segundo, depois de Tomé de Sousa, a receber o título de Governador-Geral. Ainda que os contratempos de uma viagem acidentada e afinal malograda, a que se segue a morte do governador nomeado, não permitam efetivar-se sua posse, só a escolha de um Giraldes para posto de tão alta responsabilidade, em terra que, segundo fama geral, se preservava zelosamente extreme de todo contato com estrangeiros, devia bastar para desmentir essa fama.

Pertencentes à poderosa casa bancária florentina, em íntimas relações com Lisboa, estariam os Giraldi inteiramente desvinculados de sua pátria ancestral? Cabe aqui o que disse um historiador de nossos dias, referindo-se em geral aos antigos mercadores toscanos: facciosos, suspicazes, egoístas na própria casa, fora dela, da 
pequena pátria, "deixavam de parte os rancores para sentir com todos os concidadãos uma solidariedade inspirada não apenas em razões práticas, mas em motivos ideais" (Sapori 1941: 93), que tinham sua raiz precisamente naquele apego ao lugar de origem. O certo é que Lucas, pai de Francisco Giraldes, nunca pudera chegar, apesar de sua longa residência em Lisboa, a familiarizar-se direito com a língua da terra. Dele conservou-se um bilhete, endereçado a Tomás Alegre, seu feitor em Ilhéus, onde escreveu nesta saborosa geringonça luso-italiana: "Thomazo, quiere que te diga, manda la assucre deixa le parolle" (Salvador s/d: 100)

Uma íntima e antiga comunhão de interesses ligara, em Lisboa, os Giraldi aos Affaitadi de Cremona, relacionados, por sua vez, inclusive por laços de família, aos Schetz de Antuérpia, donos do engenho de São Jorge dos Erasmos na ilha de São Vicente. Desde 1527, segundo pôde apurar o historiador belga Jean Denucé, encontramos Lucas Giraldi associado a Giovanni Francesco Affaitado no comércio do açúcar da Madeira. Os Giraldi, informa-nos também Denucé, realizaram, em negócios com as Índias e o Brasil, uma das maiores fortunas do tempo. O inventário do ano de 1568 não menciona senão 12 partes em poder dos herdeiros de Giovanni Carlo Affaitado sôbre as 97 que comportava a ragion. Os filhos de Lucas Giraldes dispunham de 50 partes, sendo que um deles, Niccola, contava com 23 (Denucé 1934: 23-4).

Outra família florentina que irá ter lugar de realce na história do Brasil, a dos Cavalcanti, fizera, por sua vez, de Londres, seu centro de operações. Giovanni, Bernardo, depois também Tommaso Cavalcanti ocuparam durante todo o reinado de Henrique VIII posição eminente nas finanças inglesas, ao lado dos Bonvisi de Lucca. Em 1544, Tomaso chega a ser o principal credor do monarca. Este não se cansava de acumular dívidas entre os capitalistas italianos de Londres até que, pouco antes de sua morte, descobriu-se que os empréstimos podiam levantar-se mais vantajosamente na praça de Antuérpia, de sorte que se tornam agora dispensáveis os serviços dos florentinos.

Bernardo Cavalcanti dirige-se a Antuérpia, onde chega em 1546 e 1556 a cônsul dos mercadores de Florença. Tommaso, que no intervalo estivera em Roma à testa da firma bancária, reaparece neste último ano em Londres, tendo deixado em seu lugar, na casa romana, Battista, ou Battista de Arcangelo Cavalcanti, mas logo depois 
surge também em Antuérpia, associado aos Affaitadi, e na mesma firma entra um Giovanni Giraldi. Ainda em Antuérpia vamos encontrar, no ano de 1563, Stratta Cavalcanti, que de sociedade com François Berty, obtém privilégio para a exploração de um processo novo de refinar sal. Em Londres também aparecem, nos anos subseqüentes, apelidos de magnatas florentinos. Já não se devotam estes, porém, com o afinco de antes, às transações financeiras ou aos tratos mercantis. Assim aponta Ehrenberg, no reinado de Isabel de Inglaterra, como residentes ali, um Guido Cavalcanti e um cavalheiro Giraldi, ambos ocupados, porém, no serviço diplomático: o último, ajunta, é embaixador de Portugal (Ehrenberg 1896: 282 e Goris 1925: 472).

O cavalheiro Giraldi é, sem dúvida, Francisco Giraldes, aquele mesmo que, tendo servido anteriormente junto à Corte inglesa, irá advogar ativamente, em 1580, perante Catarina de Médicis e Henrique III de França, a causa da duquesa de Bragança na sucessão do cardeal rei. É lícito perguntar se sua nomeação, oito anos mais tarde, para governador-geral do Brasil, não seria um modo discreto, engendrado talvez pelo próprio Filipe II ou por Cristóvão de Moura, de manter afastado do Reino um adepto fervoroso das pretensões bragantinas, só momentaneamente sopitadas.

O interesse pelo negócio do açúcar, onde sua família se viu ocasionalmente envolvida, menos, porém, do que os Affaitadi ou os Giraldi, pode sugerir uma explicação para a vinda a estas partes de Filipe Cavalcanti, patriarca do ramo que se estabelece no Brasil. Casando-se com uma filha de Jerônimo de Albuquerque e da índia Arcoverde irá tornar-se ele, por sua vez, abastado senhor de engenho em Pernambuco. Pouco se sabe sobre quando chegou. Jaboatão, seguido de outros, dá a data de 1558, mas Rodolfo Garcia oferece argumentos plausíveis para se acreditar que teria vindo pelo menos uma década antes (Varnhagen [1854] 1948: 350). Sobre as razões de sua vinda oferece o mesmo Jaboatão uma explicação que parece igualmente inaceitável: a de que envolvido com Pandolfo Pucci e outros, parentes seus, numa conjura contra Cosme de Médicis, procurou abrigo, naquele ano de 1558, em Portugal, de onde, não se achando seguro, emigrou para o Brasil.

A verdade é que a célebre conjura de Pandolfo Pucci e de outros, pertencentes à gente mais nobre de Florença, que tentarão fugir, inutilmente, aliás, porque acabam 
caçados e presos fora da Itália, não acontece em 1558, mas em 1576, quando já Filipe deverá estar fixado de longa data no Brasil. E nem se dirige contra Cosme, que já é morto, mas contra o filho e sucessor deste, Francisco I. Em era bem anterior - 1541 - o mesmo Pandolfo Pucci tivera, não tanto a vida como a liberdade, seriamente ameaçada, e só o salvou o prestígio do pai, mas dessa vez por outro motivo, por que ele e um comparsa, desafiavam descaradamente-sfacciatamente, escreve, o cronista - as novas e severas leis de Cosme I contra a sodomia (Segni 1857: 409). Note-se, entre parêntese, que também Filipe Cavalcanti se verá acusado em 1591 ante a mesa do Santo Ofício na Bahia, de ter praticado, segundo fama pública, igual pecado ${ }^{2}$, o "vício florentino", como alguns o chamavam.

Não é improvável que o bom sucesso alcançado no Brasil por esse seu conterrâneo, tanto quanto o de Lucas e o de Francisco Giraldes, deva inscrever-se entre as razões que moverão o grão-duque Fernando I a dirigir sua atenção para a América portuguesa. Numa carta de Filippo Sassetti, escrita de Lisboa a 10 de outubro de 1578 a Baccio Valori, de Florença, depara-se com o seguinte trecho que podia impressionar os seus conterrâneos:

"Do Brasil chegam também açúcares, na maior parte brancos, e valem cada 43 libras, quatro ducados. Vive naquele país Filipe Cavalcanti, o irmão de Guido e de Stratta, o qual dispõe de vastíssimos cabedais e é homem de grande autoridade, quase sobranceiro a todos, até ao próprio governador. Conta-se que tem grande estado, com muitos pagens e cavalos, gastanto cada ano em sua casa mais de cinco mil escudos, e seus negócios são engenhos de açúcar" (Sassetti s/d: 127).

Do documento $10^{\circ}$, que a seguir se pode ler, e que suponho ainda inédito, tira-se que, por volta de 1618, data do texto, ainda seria vivo Filipe, pai do Jerônimo Cavalcanti d'Albuquerque, a quem o mesmo se refere "la cui casa e padre vivono nel Brasile" -

\footnotetext{
${ }^{2}$ Primeira Visitação do Santo Officio às Partes do Brasil - Denunciações da Bahia, São Paulo,
} 1925: 452. 
o que não condiz com informações de Borges da Fonseca, o genealogista. Segundo este, sobreviveu Filipe alguns anos a Jerônimo de Albuquerque, seu sogro,

"Porém ultimamente faleceu, deixando ainda viva sua mulher D. Catarina de Albuquerque, a qual foi perfilhada a pedido de seus pais pelo senhor rei D. Sebastião, e faleceu com mais de 70 anos, no de 1614, a 4 de junho...".

Se Filipe ainda vivia em 1618, e teria chegado ao Brasil pelo ano de 1548 ou antes, como quer Garcia, devendo já ser homem feito, pode presumir-se que morreu quase centenário. O Jerônimo Cavalcanti de Albuquerque, de quem trata o documento $10^{\circ}$, foi o filho quarto do mesmo Filipe. Copio aqui o que dele escreveu Borges da Fonseca, e pouco mais se sabe a seu respeito:

“... Cavaleiro da Ordem de Cristo, cujo hábito tomou em 1634. Era senbor de três engenhos em Goiana como escreveu o $4^{\circ}$ Donatário Duarte d'Albuquerque nas suas Memórias da guerra de Pernambuco, quando se viu obrigado por causa das mesmas guerras a retirar-se para a Babia, no ano de 35. Daquela cidade passou a Lisboa, onde alcançou o governo do Cabo Verde, e faleceu solteiro e sem sucessão" (Fonseca 1935: 413).

Já agora também sabemos que bem antes disso andou em Lisboa. Não consegui achar as cartas que a Sua Alteza Sereníssima, então Cosme II, primogênito e sucessor de Fernando I, mandava seu Secretário de Estado em nome deste Jerônimo Cavalcanti d'Albuquerque. O fato, porém, de dirigir-se este ao grão-duque, quando mais não fosse, para lhe pedir talvez alguma certidão de nobreza ou uma confirmação da que a Filipe, seu pai, passara em 1519 Cosme I, é sem dúvida sugestiva de como a ancestralidade florentina continua ainda viva no filho de Dona Catarina, a mameluca pernambucana.

Pelos três primeiros documentos da série anexa, vê-se como o grão-duque Fernando começara por alimentar esperanças exageradas sobre a possibilidade de estabelecer um comércio regular com o Brasil, e eventualmente com as Índias Orientais, através de navios estrangeiros, quer dizer não portugueses, nem espanhóis, e nem necessariamente toscanos, os quais iriam diretamente a Liorne, carregados de mercadorias, principalmente açúcar e pau-brasil, sem precisar tocar em Lisboa 
ou em algum ponto qualquer das Espanhas. Numa das cartas chega-se a falar num pedido de licença para a ida cada ano de oito navios, através de uma década, o que perfazia o total de oitenta navios, número esse que a Francisco Lanzoni, seu embaixador junto ao rei católico, não deixa de parecer excessivo.

Relacionava-se o plano, intimamente, à sua ambição de ver instalado em seus domínios o lucrativo negócio das refinarias de açúcar, tais como as havia em Flandres ou Veneza, e pode ter sido fomentado pelas notícias do comércio direto e não autorizado que outros povos - os hanseatas, por exemplo, até 1602 - faziam e continuariam a fazer com o Brasil ${ }^{3}$. Não é impossível que até marinheiros toscanos tivessem participado de alguma dessas expedições clandestinas, pois certa passagem de Galuzzi, que pode ter tido em mãos documentos hoje desaparecidos dos arquivos, alude em seu livro ao comércio clandestino que nas costas brasileiras costumavam praticar os marinheiros da Toscana (Galuzzi 1781: 257). A dificuldade estava nisto principalmente, que dispondo embora de apreciável frota bélica, o grão-ducado não tivera ainda tempo de preparar em escala considerável embarcações pacíficas ou especialmente adequadas à navegação fora das águas do Mediterrâneo. De onde o alvitre de recorrer a barcos estrangeiros, não toscanos, e nem espanhóis ou portugueses, para o bom sucesso da empresa projetada.

Não lhe devia parecer custoso, ao grão-duque, valer-se agora dos préstimos dos Ximenes, ativos comerciantes portugueses, que dispunham de ampla rede de correspondentes em vários lugares da Europa. Agora mesmo já se dispunham a abrir casa em Florença ou Pisa, com o que se colocavam ao seu alcance direto. Fernando I apressava-se em tirar o melhor proveito para si e para o Principado da troca de favores

\footnotetext{
${ }^{3}$ Sobre o comércio hanseata com o Brasil no século XVI ver Baasch (Dr. Ernst), "Beiträge zur Geschichte der Handelsbeziehungen zwischen Hamburg un Amerika", Hamburgische Festschrift zur Erinnerung an die Entdechung Amerika's, vol. 1º, Hamburgo, L. Friedrischsen \& Co, 1892: 91ss. Ver principalmente os estudos mais recentes de Kellenzenz (Hermann), Unternehmerkräfte im Hamburger Portugal - un Spanienhandel, Hamburgo, 1954: 51-3, aproveitados em Sérgio Buarque de Holanda (diretor) História Geral da Civilização Brasileira, I: 164ss.
} 
inevitável e, mais do que isso, era como se já visse realizado o que em nossos dias pôde escrever Braudel, repetindo o velho Galuzzi: “... les Ximenes qui marchand portugais se firent Florentins" (Braudel 1949: 616).

Não poderia falar-lhes como de soberano para súditos? Não quis o Médici, nem lhe convinha, seguir esse caminho reto, prevendo nele estorvos insuperáveis. Resulta dos textos anexos (Documento 1) que desde $1^{\circ}$ de outubro de 1591 pelo menos, escrevera pessoalmente a Tomás Ximenes, pedindo-lhe a intercessão junto à Coroa de Espanha em favor de seu projeto de comerciar diretamente com o Brasil, Cabo Verde e talvez a Índia. Pela mesma época, Fernando Ximenes, irmão de Tomás, tratava dos interesses do grão-duque em Hamburgo, ocupando-se do comércio de grãos com a Toscana (Kellenbenz 1954: 242). A realização do plano, tal como o concebera a princípio não deixava de oferecer dificuldades, envolvendo-o num verdadeiro círculo vicioso. Realizar o negócio por meio daquela casa de marranos, ainda que não judaizantes, era dar parte do lucro a eles, e isto não queria o grão-duque. De outro lado, não podia tratar diretamente com a Coroa espanhola sem o conhecimento deles, pois o próprio Tomás Ximenes era amigo e familiar de D. Cristóvão de Moura, cuidando dos seus negócios em Portugal, e nada se podia fazer no Conselho de Sua Majestade a respeito do Brasil, sem primeiramente ouvir D. Cristóvão.

Além disso, não podia haver ainda notícia segura quanto ao estabelecimento dos Ximenes na Toscana. Isto mesmo irá dizer ao grão-duque seu embaixador em Madrid (Documento 2):

“... porque no que respeita à transmigração destes mercadores destes reinos e de Portugal, não se vá fiar muito disso Vossa Alteza, que só hão de ter uma sua casa aberta em Pisa ou Florença, com um deles que atenda aos negócios, como o fazem em Flandres, Lisboa ou outras partes deste Reino".

Infelizmente fazem falta estudos especiais acerca da ramificação florentina dos Ximenes, apesar dos trabalhos valiosos e pioneiros de Denucé, Kellenbenz e Gentil da Silva, que entretanto só tocam fugazmente no assunto. 
Depois de abril de 1592 irá desaparecer o nome dos Ximenes da correspondência ducal sobre coisas brasileiras, mas nem por isso, com todos os obstáculos encontrados, renuncia Fernando I aos seus sonhos. Não é sem interesse, nesse particular, a carta igualmente inédita de 1 de julho de 1595, que aqui se divulga (Documento 4), onde seu embaixador Francesco Guicciardini, homônimo e certamente parente do grande Guicciardini, morto muito antes disso, acentua a nenhuma resistência que encontraram os marinheiros ingleses de James Lancaster em Pernambuco e a vultuosa prêsa que ali arrebataram.

O documento não nos traz nenhum fato novo a respeito da ação de Lancaster, mas é bem sugestivo do interesse que a notícia podia despertar na Toscana. O inglês apresentou-se diante do Recife a 9 de abril e permaneceu um mês inteiro naquele porto. A 10 de junho já se podia mandar aviso do sucesso para Florença. É evidente que Fernando não cogitava senão de realizar pacificamente seus projetos brasileiros e nem podia pensar seriamente em lançar qualquer desafio ao poderio espanhol. Nem por isso deixaria de impressioná-lo, porém, a facilidade extrema com que súditos de outra nação eram capazes de semelhante proeza. Mais tarde acolherá em sua Corte a Sir Robert Dudley, que acompanhara com interesse as ações de Lancaster $^{4}$ e que haverá de incitar o grão-duque a patrocinar, dissimuladamente, embora, sua aventura amazônica.

Apesar de todos os tropeços encontrados até aquele momento, a insistência de Sua Alteza Sereníssima em querer alcançar permissão para a navegação e o comércio do Brasil (Documento 5) e sua esperança no bom sucesso das negociações nesse sentido, ainda que a custa de propinas distribuídas a altos funcionários castelhanos ou portugueses, tinha em que sustentar-se. Afinal a lei de Filipe II proibindo, a 9 de fevereiro de 1591, a navegação estrangeira para os domínios ultramarinos de Portugal não era terminante, pois só vedava aos mesmos estrangeiros o irem sem licença àqueles lugares, e o que pelejava por obter o grão-duque, por ora, era apenas uma tal licença.

\footnotetext{
${ }^{4}$ The Voyage of Sir James Lancaster to Brazil and the East Indies, Londres, Printed for the Hakluyt Society, 1940: XXIV.
} 
Ainda em 1605 escrevia-Ihe o embaixador Tarugi, de Valadolid, em resposta a carta de S. A., dizendo que oportunamente abordaria o caso da licença, só não o fazendo logo, por não se ter ainda expedido um outro assunto, "quell'altro negozio", pendente ainda, e não convir tratar ao mesmo tempo de dois casos, maximamente, ajunta, por ir "contra uma lei modernamente feita, a qual revoga todas as licenças que porventura tivessem sido concedidas" (Documento 6).

A carta é de 4 de junho. A lei "modernamente feita", tem a data de 18 de março do mesmo ano de 1605, e alega, com efeito, que tendo sido anteriormente concedidas licenças a estrangeiros de nações amigas para ir aos domínios portugueses, aproveitaram-se eles mal dessas licenças, falsificando outras para inimigos do que resultava grande prejuízo para o Reino. Por isso publicava-se a lei nova, proibindo a qualquer navio de nação estrangeira o ir à Índia, Brasil, Guiné, Ilhas, e quaisquer outras províncias do senhorio de Portugal. Mesmo aqueles estrangeiros residentes ou estantes em alguns dos ditos domínios, deles deveriam sair, sendo concedidos aos que se achassem no Brasil, e "mais partes ultramarinas de Cabo da Bôa Esperança pera cá”, o fazerem no prazo de um ano (Rau e Silva 1955: 10).

É possível que só depois disso, desalentado com as notícias idas da Espanha, tenha enveredado o grão-duque por outros caminhos mais tortuosos, os quais, se publicados não seriam de molde a bem sustentar suas relações com a Coroa espanhola. A carta a ele endereçada sobre as perspectivas de fazer-se o comércio com as Índias Orientais e o Brasil, recorrendo a armadores e capitalistas de Amsterdã, é certamente de 1608 e, mais certamente, é uma resposta a sondagens suas. O simples fato de aparecer sem data e assinatura não atenderia ao intuito de ter encobertas todas as pistas? A ida da expedição secreta à Amazônia é de setembro ou outubro do mesmo ano de 1608. Confiada a marinheiros ingleses é por ele patrocinada, embora seu nome não devesse aparecer no negócio. E se fosse forçoso que aparecesse responsável, que o atribuíssem vagamente a mercadores de Florença.

De súbito, porém, muda de tática e tenta embarcar num projeto ainda mais ambicioso do que os anteriores: o da remessa de colonos ao Brasil, precisamente à capitania do Espírito Santo, conforme consta de carta sua de 9 de novembro de 1608, 
posterior de dois meses apenas, ou menos (Documento 7), à empresa de exploração do rio Amazonas. A mudança deve prender-se provavelmente ao fato de ter recebido no intervalo, datada de Lisboa, 30 de agosto, uma carta assinada pelo engenheiro florentino Baccio de Filicaya, o qual tendo servido longamente no Brasil com D. Francisco de Souza e Diogo Botelho, indiretamente animava S. A. S. a novos empenhos junto à Coroa de Espanha.

A carta, em filza 949, folhas 1346 a 1349 do arquivo mediceo, traz no verso da fl. 1347 estes dizeres do Secretário Vinta: "Que o Filicaya mande nova relação por escrito de todo o país e viagem que fez, com mais particularidades possíveis de notícias, por curiosidade de Sua Alteza, ouvindo de bom grado estes avisos".

A 5 de janeiro respondia o Filicaya, anunciando que já tinha pronta a descrição (junto com uma relação) do país, e por ser volumosa deixava de mandá-la pelo correio, reservando-se para enviá-la numa urca que seguia aquele mês para Veneza. Nem a relação nem a descrição foram até aqui achadas no arquivo de Estado de Florença. Todos os papéis que lá se encontravam acerca de Filicaya, suas duas cartas e duas outras de Fernando I, sendo uma ao seu embaixador na corte de Espanha e a segunda a D. Cristovão de Moura, publicou-os Giacomo Gorrini em 1903 (e em parte já em 1901, Gustavo Uzielli nos Cenni Storici), de onde, vertidas para o português, foram incluídas em nota de Rodolfo Garcia a Varnhagen. Por esse motivo dispenso-me de reproduzi-las aqui.

Não há sinal de outros passos que tivesse dado o grão-duque na esperança de ver concretizado seu novo e mais ambicioso plano. Enquanto aguardava notícias sobre o projeto de colonização no Espírico Santo, ainda procurava alimentar sua curiosidade teimosa de terras remotas, indagando acerca da Serra Leoa, possivelmente mais acessível do que o Brasil ou menos zelosamente guardada. Esse, o objeto da carta endereçada ao cardeal Maria Francesco de Santa Maria, em Roma, à véspera quase do ano novo de 1609 (Documento 8). Morreu logo depois sem ter tido tempo sequer de saber o resultado da expedição que mandara ao Amazonas.

Sob seu sucessor Cosme II ainda há algum sinal de tentativas semelhantes de expansão econômica ou política do Principado, mas essas mesmas se fazem agora 
mais espaçadas. Uma carta do embaixador à Corte espanhola, datada de outubro de 1612 trata de dissuadi-lo da idéia, que já se tinha suscitado sob o grão-duque seu pai, de serem mandados dois navios à Índia - já não se fala expressamente em Brasil fora das frotas regulares, porque "o rei nunca o permitiria" (Documento 9). Parece que daí por diante se limitam os agentes toscanos a mandar notícias sobre a partida e chegada das frotas, em avisos do teor deste, que é de 8 de agosto de 1618: "De Lisboa informa da chegada da frota do Brasil, que traz, na maior parte, açúcar; mas das naus das Índias orientais não há mais novas. Esperamos sua vinda a cada momento".

\section{Referências Bibliográficas}

BARBOUR, Violet. Capitalism in Amsterdam in the $17^{\text {th }}$ Century. Ann Arbor, The University of Michigan Press, 1963.

BRAUDEL, Fernand. La Méditerranée et le Monde méditerranéen à l'époque de Philippe II. Paris, Librarie Armand Colin, 1949.

DENUCÉ, Jean. Inventaire des Affaitadi, Banquiers Italiens a Anvers de l'Année 1568. Antuérpia, 1934.

EHRENBERG, Richard. Das Zeitalter der Fugger. Jena, 1896.

FONSECA, Antonio José Vitoriano Borges da. Nobiliarchia Pernanbucana, vol. 1. Anais da Biblioteca Nacional do Rio de Janeiro, vol. 47, Rio de Janeiro, 1935.

GALUZZI, R. Istoria del Granducato di Toscana sotto il governo di Casa Medici. Florença 1781.

GORIS, J. A. Étude sur les Colonies Marchandes Meridionales à Anvers de 1488 à 1567. Louvain, Librairie Universitaire, 1925.

HAKLUYT, Richard. The Principal Navigations Voyages Traffiques \& Discoveries of the English Nation, vol. $7^{\circ}$, Londres e Toronto, J. M. Dent and Sons Lted, e Nova York, E. P. Dutton \& Co., 1927. 
RAU, Virginia e SILVA, Maria Fernanda Gomes da. Os Manuscritos do Arquivo da Casa de Cadaval Respeitantes ao Brasil. Vol. 1º, Coimbra, Por Ordem da Universidade, 1955.

RIDOLFI, Roberto. "Pensieri medicei di colonizzazione nel Brasile", Il Veltro. Rivista della Civiltà Italiana, Roma, agosto de 1962.

ROOVER, Raymond de. The Rise and Decline of the Medici Bank. Nova York, The Norton Library, 1966.

SALVADOR, Frei Vicente. História do Brasil. $3^{\mathrm{a}}$ edição. São Paulo, Companhia Melhoramentos, s/d.

SAPORI, Armando. Mercatores. Milão, Garzanti, 1941.

SASSETTI, Filippo. Lettere. Milão, Casa Editrice Sonzogno, s/d.

SEGNI, Bernardo. Istorie Fiorentine dall Anno MDXXVII al MDLV. Florença, Barbera, Bianchi \& Co., 1857.

UZIELLI, Gustavo. Cenni Istorici sulle Imprese Scientifiche Marittime e Coloniali di Ferdinando I Granduca di Toscana. Florença Pei Tipi di G. Spinelli \& Co., 1901.

VARNHAGEN, F. A. de. História Geral do Brasil. $4^{\text {a }}$ edição. São Paulo, Edições Melhoramentos, 1948. 


\section{DOCUMENTOS}

\section{Documento $n^{\circ}$ I}

Archivio di Stato di Firenze

Archivio Mediceo, filza 492i, c. 405.

Serenissimo Granduca.

Mi è stata presentata da Tommaso Ximenes $(*)$ una lettera di V. A. de 30 de ottobre passato in sua raccomandazione et per favore di ottener licenzia di far partir dal Brasil dieci navi forestiere cariche di mercanzia et inviarle a Livorno con pagare tutti li diritti. Io, conoscendo la lettera di V. A. efficace et la qualita della persona di buona maniera, essendo stato informato di questi fratelli Ximenes $\left(^{*}\right)$ et della lor risoluzione già è più d'un mese da Monsignor Pinto (*), me li offersi con ogni sorte di dimostrazione, quando V. A. li tenga in protezione et credo ne rimanesse con sodisfazione, ma come pratico et prudente mi pregò che del negozio delle dieci navi (*) io non ne trattassi, essendo impossibile si per li ordini di Portogallo, quali non suole Sua Maestà, alterare che questa navigazione (*) si facci solo da Spagnoli et navi spagnole (*), le quali sieno obligate venir a Lisbona (*) o cert'altro luogo determinato, vicino, debbino pagar li diritti et di quivi poi possono andar dove vogliono, soggiungendo che quando si sapesse il lor nome et interesse non mais s'otterrebbe per questa loro destinata dispopulazione (*) che non pensi V . A . che sia ben sentita . Hora ragionando risolvemmo che in genere, come da me, vedessi com Don Giovanni Idiaque se fussi riuscibile, tacendo il loro nome reo (*) servendomi del nome di V. A. per suoi amici et per suo servitio come farò in buon proposito. Ma tanto piu bisogna tener amore del Consiglio di India, di quei del Consiglio di Spagna et quel del regno d'Inghil terra (*) come è stato scritto.

Di Madrid li 15 diciembre 1591.

Humilissimo servo Francesco Lenzoni.

(*) Palavras cifradas no original. 


\section{Documento $n^{\circ} 2$}

Archivio Mediceo filza 4921, carte 516-517

Mi è venuto questo giorno a trovare Tommaso Ximenes et con dirmi prima che non tiene di quelle due navi da suo figliolo altra riposta di che mi sono un poco riso in me stesso, et con dirmi che in questo giorno si passa 1'instrumento in Portogallo del loro appalto delli pepi da condursi d'India in quel Regno, come scrissi a V. A. essersi trattato e quasi conclusa la capitolazione nella mia lettera de' 24 di gennaio passato (**), della quale aspetto risposta per causa del discorso del secondo appalto de'pepi condotti in Portogallo. Mi ricercò il Ximenes di quello che V. A. mi comandava favorirlo per la sua lettera de'30 d'ottobre passato, e di che io gli avevo offerto ogni mio potere secondo il suo comandamento, ma come gli scrissi nella mia del 15 di dicembre passato, ma che egli mi haveva pregato a soprasederne ogni mio ragionamento parendoli quasi impossibile l'ottener licenzia di far partir dal Brasil dieci navi forestiere e non portoghesi, cariche di mercanzie ed inviarle a Livorno con pagarne li debiti diritti, secondo che V. A. mi commandava di favorirlo, et non solo per esser questa navigatione solo di portoghesi, et con navi portoguese, ma per doversi fermar nel Regno in certo determinato luogo, et quivi pagar li diritti secondo li statuti antichi di quel Regno, oltrechè non credeva esser ben sentito la sua passata con aprir casa in Fiorenza. Ma hora o vero che si contentassi allhora di soprasedere per trattar 1'appalto de'pepi d'India, o vero che si risolvessi servire di questa occasione di aprir casa in Fiorenza, per accomodar meglio li suoi negotii con questi ministri regi di molta importanza, perchè quanto al dispopolare questi Ximenes di questi Regni e di Portogallo non lo creda mai V. A. ma solo terrano una lor casa aperta in Pisa o in Fiorenza con un di loro per attendere a quelli negozii, come fanno in Fiandra, in Lisbona e in altre parti di questo Regno, o vero che li sia paruto tener io in buona reputazione in trattare con questi ministri et esser udite le cose di V. A. con degnità et non come si credeva in principio, però, qual sia di queste cause la vera, mi ha pregato che vogli cominciar questo negozio con darne memorial a $\mathrm{Su}$ Magestad e dicendoli io che non mancherei fare quanto V. A. mi veniva commesso, con ogni diligenza lo ricersi che mi mandasse un poco di informazione di quelli ordini di Portogallo per poter formare il Memorial concludente. Dopo esser partiti mi mandò subito 1'incluso biglietto et forma di quanto si deve domandare et veggo che di otto navi di zuccheri dal Brasil e San Tomè per qualunche anno per dieci anni et cosi viene per ottanta navi che

(**) A carta aqui mencionada e que vai de fls. 450 a 458 do códice, trata dos negócios de Tomás Ximenes em torno da pimenta da Índia. Não se refere ao Brasil, razão pela qual deixa de ser incluída entre estes documentos. 
mi pare somma importante. Ci è intermedia la malattia di S. Maestà che per questo negozio porterà molta dilazione, però potrò ricever in questo mentre li comandamenti di $\mathrm{V}$. A. non solo circa il numero delle navi et degli anni, ma, ma se questo memoriale vuol esser in nome di V. A. perchè ottenendosi ne possa disporre con qualunche a suo beneplacito opure a nome delli Ximenes, i quelli, ottenendosi ne potranno, come per Livorno, dispor per tutta Italia parimenti. Mi scriva V. A. 1'intenzion sua chiara in questo negozio.

Di Madrid, li 1 marzo 1592.

F. L.

\section{Documento $\mathrm{n}^{\circ} 3$}

Archivio Mediceo, filza 4921, cc. 57071.

Scrissi a V. A. nella mia de' 15 di marzo passato come venino ricercato da questo Tommaso Ximenes di procurar da S . Maestà facultà di poter far venir dal Brasile e San Tomme per dieci anni otto nave per qualunch' anno, forestieri e non portoghesi, cariche di zuccheri, con pagar li soliti dazii, alla diritta per Livorno, senza fermarsi in altri luoghi, nonostante li ordini di Portogallo nell'uno nell'altro capo delli ordini predetti, et dissi a V. A. che per la malattia di S. Maestà ci saria tempo d'aspettar li comandamenti di V. A., non solo circa il numero degli anni e delle navi, ma si il memorial doveva esser in nome di V. A., essendo questo negotio importante. Ma di poi, havendo ricevuto la sua ultima lettera de'23 di febbraio, dove in riposta della mia lettera de' 24 di gennaio passato, nella quale io li havevo trattato dell' appalto de'pepi dell'India a Lisbona, concertato da questi Ximenes, restandoci 1'altro d'appaltare li pepi condotti a Lisbona per mandarli in tutte le parti con includervi li crediti de'mercanti et proprii di V. A. con questa Maestà, et che Tommaso Ximenes si offeriva intervenir per la metà in questo negozio, mi ha dichiarato $\mathrm{V}$. A. non esser sua impresa d'interessarsi altrimenti, non per la detta risposta di V. A. che non m'è paruto bene aprirgliene, ma come da me stesso e di mio pensiero, che non tratti più oltre con Don Cristofano de Mora del quale è familiare et agita le sue faccende in Portogallo, sopre questo secondo concerto dell' appalto de'pepi condotti in Portogallo, con esortarlo che conducendo per se stesso e suoi fratelli questo appalto di far più scala a Livorno che può, di queste et altre mercantie, mi sono insieme resoluto di non tentar il memorial delle navi ottanta in dieci anni di zuccheri del Brasil e San Tomme per Livorno, perchè intendendo V. A. non esser opportuno interessare il suo nome o li suoi effetti in questi negozii sotto nome de'Ximenes, oltre che seria nonchè difficile quasi impossibile ottenerlo, mi par negozio di tanto profitto che senza suo expresso comandamento non si dovessi affaticar per altri non ci essendo alcun interesse di gran lunga equivalente. Però, come ho dato 1'esclusion del 
negozio d'pepi, così di questo memoriale ne darò lunghezza tale che sarà esclusione, non mi ci intromettendo senza preciso comandamento di V. A., più altrimenti.

Di Madrid li 25 di aprile 1592.

F. L.

\section{Documento $n^{\circ} 4(* * *)$}

Archivio Mediceo, f . 4923, c.716.

Di Lisbona ci fu alli giorni passati avviso come in quel P. [ porto ] era arrivato un vasseletto che veniva del Brasil a posta per dar nuova come 12 vasselli inglesi erono entrati nel porto di Pernambuch, principal luogo di quella costa, et havendo senza resistenza alcuna sbarcati cinquecento fanti in terra, si erono inpadroniti del forte che sta alla marina per guardia del porto, dove havevono trovato si bene 1'artiglieria ma non già nè chi la guardasse nè chi la scaricasse et che perciò havevono potuto con intera comodità svaligiare quei magazzini che son posti più basso fuori della terra, alla marina, ne'qualli oltre a una grossa quantità di zuccheri et di legno del proprio Verzino, havevono trovato anco tutto il carico d'una delle navi d'India orientale, che 1'anno passato, havendo diritto il suo viaggio secondo il solito a Lisbona, fu constretta a scaricar la mercanzia nel detto Porto di Pernambuch non potendo passar più avanti per la molta aqqua che faceva, si che fanno conto che questo bottino fatto dagli Inglesi importi più di 500 mila scudi et molti vogliono dire anco d' 800 mila et che così non haranno per perso il lor tempo a fatto.

Di Madrid li 10 luglio 1595.

Humilissimo et devotissimo servitore.

Francesco Guicciardini

(***) De um relatório de 10 págs. sobre coisas de Espanha. O texto transcrito é a única parte relativa ao Brasil. 


\section{Documento $n^{\circ} 5$}

Archivio Mediceo, f . 4923 c. 791.

V. A. mi scrisse più mesi sono che li mercanti della sua città di Fiorenza haverian desiderato ottener grazia da S. M. tà di poter navicare un numero di tante navi di zucheri del Brasil a Livorno a dirittura senza tornare in Portogallo, con pagare li soliti diritti, et io avendo fatto diligenzaper sapere particolarmente se questa era grazia da poterla tentare con speranza d'ottenerla, trovai, come scrissi all'hora a V. A., et per le ragioni che io le allegai, che non ci era che sperare. Ultimamente trovandosi in questa città per alcuni suoi negozii Raffaello Fantoni gentilhomo fiorentino et devotamente vassalo di V. A., che già molti anni sono risiede in Lisbona dove è casato et negozia mercantilmente, et è molto pratico delle cose di quella corona, dalla quale haveria a depender questa grazia, havendoli io profferito questo pensiero de' mercanti fiorentini per sentirne la opinion sua, mi ha disposto, che per le vie ordinarie tiene per impossibile ottenere questa grazia. Però che con qualche arbitrio o proposizione che potesse dar gusto a quella corona che giudicherebbe un util per se stesso et da potere anco sperare di cacciarli in groppa questa comodità di navicare li zuccheri, del quale havendomi egli dato una memoria assai distinta m'è parso di inviarla $\mathrm{a} \mathrm{V}$. A. perchè la possa farla considerare et trovandoci alcuna cosa di buono per il servizio delli suoi stati et vassalli, servirsene. Et quando 1'A. V. trovasse che da cotesti mercanti non fusse stimato il negozio de'pepi di tanto profitto che meritassi il pregio mettersi in esso per ottenere la facultà di navicare li zuccheri, si potria tentare d'includere in esso alcuna parte del credito di V. A. o de'mercanti, con questa corona, 1'uno et 1'altro de'quali è a mio giudizio cosa vana il sperar di avere a risquotere mai per le vie ordinarie, sebbene anco per questa della compera de'pepi ci doveria esser delle difficultà per essere il debito della corona di Castiglia et li pepi di quella del Portogallo, che malvolentieri, tuttoché il patrone sia 1'istesso confondono 1'interesse dell'una con quelle dell' altra, le quali difficultà non ostanti, è parso a me dover dar parte di tutto questo all'A. V. et mandarle 1'informazione stessa datami di questo suo buon vassallo.

Di Madrid li 9 di settembre 1595.

F. G. 


\section{Documento $n^{\circ} 6$}

Archivio Mediceo, f . 4933, c. 561.

Ser. mo Signore Principe Colendissimo.

Sopra il negozio della licenza di poter mandare navi al Brasil et altri luoghi soggetti alla corona di Portogallo, resto ben capace del desiderio et intenzione dell' A. V. et ne tratterò a suo tempo, spedito quell'altro negozio di quell'avviso, del quale mi si deve dar nota parendomi che pendente questo, non sia bene dimandar cosa veruna, et massimamente contra una legge fatta modernamente con revocatione di tutte le licenze che fussino state concesse.

Di Valladolid 4 de giugno 1605.

Di V. A. S. ma humilissimo et fedelissimo servo et vassallo.

Sallustio [Tarugi] vescovo di Montepulciano.

\section{Documento $\mathrm{n}^{\circ} 7(* * *)$}

Archivio Mediceo, f . 4939, c. 638.

Con 1'esempio di don Pedro nostro fratello, noi andiamo considerando d'impiegar qualcuno de'nostri secondo o terzo geniti fuori di questi Stati et accomodarli che habbino le loro entrate lontano dal primogenito. Per questo cercammo di fare 1'impresa di Cipro et siamo andati pensando d'acquistare in diversi luoghi nel Regno di Napoli, ma ci è cascato le braccia per vedere i mali tratamenti che si fanno là et le insolenze de'Viceré. Ultimamente ci è venuto in considerazione di procurar qualche luogo alla nuova Spagna o alla Costa del Brasil, dove con i nostri denari si potesse andar ampliando a dosso a quelli Indiani, i quali, mediante questo, si pottrebono ridurre alla fede Christiana et all'ubbidienza di Sua Maestà Cattolica. Sappiamo che la Corona di Spagna et quella di Portogallo hanno usato non solo di donare alli acquistatori il paese che acquistano, ma ancora di favorirli come hanno fatto a diversi. Et hora, havendo noi notizia d'un luogo nella detta Costa del Brasil sotto la corona di Portogallo, che si chiama lo Spirito Santo et è in feudo perpetuo a certi Postoghesi, noi contratteremmo volentieri con loro perchè dicono che v'è gran paese daacquistare et in buona aria et che v'è anche un poco di porto da potervi ricever de'vasselli di circa 800 salme. Questo luogo con i denari et col mandarvi de'Mori si potrebbe augmentare, ma bisognerebbe

(****) Carta de Ferdinando I, grão-duque de Toscana a Sallustio Tarugi, bispo de Montepulciano e seu embaixador junto à Corte de S. M. Católica. 
haver licenza da cotesta Corte di potervi mandare un par di vasselli a caricare dí quelle robe che vi si trovano, per veder bene il paese innanzi che c'imbarchiamo più oltre, perché per entrare in simili negozi bisognano poi molte spese; et però innanzi di farne la compra bisogna molto ben considerare ogni cosa. Crediamo che Sua Maestà havrebbe da stimare suo servizio d'havere in quei paesi un nostro figluolo, il quale, con suaparte che noi gli daremmo, potrebbe andar debellando quegli infedeli. Ci sono anche molte altre ragioni, le quali V. S. si può facilmente immaginare et però tralasciamo.

Basterebbe adunque haver licenza di potervi mandar ogn'-anno due vasselli per tanti anni quanti paresse a Sua Maestà, i quali vasselli potessero andar et venir liberamente, pagando alla Maestà Sua i diritti com'è dovere. Et perché nel detto paese si ricoglie poco zucchero, si verrebbe a cavar utile di una cosa che hora non è in alcun prezzo, cioè del legno sassofrasso, del quale vi è quantità et verrebbe fresco et noi medesimi ne adoperiamo per la nostra sanità, ma perché non ce ne viene del fresco si getta via la maggior parte. Si potrebbe anche nel medesimo paese andar cercando se vi si scoprissero delle miniere, ancorché fino a hora non se ne habbia notizia, anzi è opinione che non vi se ne trovi. Vi è ben del legname il quale, quando bisognasse per servitio di Sua Maestà, sarebbe buono a fabricar vasselli da mille salme in giù et vi si manderebbon de'maestri per farne. Et si vede che tra i vasselli d'Olanda son molti che non passano mille salme et pur se ne servono da guerra.

Diremo anche a V. S. per sua notizia sola che alcuni mercanti hanno mandato a quel luogo un vassello che è andato in 65 giorni et tornato in 60 , ma non ha potuto caricar nulla perchè v'era andato un Visitatore; ma basta vedere che vi si può andare in pochi giorni et con facilità. Tutto il nostro pensiero, come abbiamo detto, è d'impiegare uno di questi nostri figlioli lontano del Principe; il cche dovrebbe piacere anche costò, essendosi dato moglie al Principe una sorella della Regina; perchè questo paese genera cervelli tanto sottili che i fratelli il più delle volte non convengono insieme, et perb vorremmo tenerli separati.

9 di novembre 1608 . 


\section{Documento $n^{\circ} 8(* * * * *)$}

Carta de Ferdinando I ao Cardeal

Maria Francesco del Monte Santa Maria em Roma

29 di dicembre 1608

V. S. Ill. ma sa il diletto ch'io soglio havere dalle notizie delle cose del mondo, particolarmente di paesi marittimi; e però, havendo alcune volte sentito ragionare d'una provincia d'Affrica sul mare Oceano, poco sotto al Capo Verde. chiamata la Sierra Liona, la quale non son molt'anni che dal Re di Spagna fu donata a Pedro Alvarez Perez suo Segretario ne'negozi di Portogallo, io havrei molto desiderio di procurarne una relazione più minuta che fosse possibile, e perchè io so che nella detta provincia sono stati piü volte i Gesuiti, e è verisimile che da qualcun di loro ne siano state fatte delle historiette, e che forse sia oggi in Roma alcuno di detti Padri che vi sia stato e ne sappia molto ben ragionare, prego V. S. Illustrissima che lo desidero, e trovandosene forse libri o scritture o in stampa o in penna, mi sarà carissimo di haverne copia, o di poterle in qualche modo vedere; e a V. S. Illustrissima bacio le mani.

\section{Documento $n^{\circ} 9$}

Archivio Mediceo f . 4942, c. 234.

Per conto del riarmare i nostri Galeoni ho visto la scrittura che S. A. mi manda et havendone parlato, come da me più volte con il Sig. Don Diego Broccero et particularmente questa sera, che è stato qui a vedermi, trovo che il far la petitione nel modo contenuto in detta scrittura haverà quasi dell'impossibile; perchè il Re non permetterebbe mai che andassero navili all'Indie senza partire et tornare con le flotte et senza caricare et discaricare in Sivilia se ben questo che i navili di S. A. potessero passar liberamente senza obligo di discaricare in Sivilia sarebbe più facile ad ottenersi.

(*****) Impresso em Uzielli (Gustavo), Cenni Storici sulle Imprese scientifiche Marittime e Coloniali di Ferdinando I. Granduca di Toscana (1587-1609), In Firenze, Pei Tipi di G. Spinelli \& C., 1901. 
Don Diego Brocero è restato meco di scriver questa sera al Sig. Duca di Lerma sopra il negotio per pigliar 1'ordine di S. Maestà di poter trattar meco delle conditioni nelle quali cercherò il maggior vantaggio di $\mathrm{S}$. $\mathrm{A}$. che sarà possibile et non fermerò nulla senza darne prima conto costà, supplicando intanto S. A., nostro Signor che faccia considerare di nuovo quel che li possa importar d'utile il mandar due navi all' India, quando ben 1'ottenesse come pretende in questa scrittura, perchè qui è cocmune opinione degl'intendenti che hoggi la contratatione con gl'Indiani sia di poco frutto et tanto meno se non la conseguissimo se non limitatamente et nel modo che vanno 1'altre navi spagnuole si che non sia forse da disprezzare quel negotio del sale, o vero proporre qualch'altro modo più sicuro et più utile come ce n'andremo ingegnando Don Diego Brocero et io per trovar cosa che stia bene a tutti.

16 di ottobre 1612

\section{Documento $\mathrm{n}^{\circ} 10$}

Archivio Mediceo f . 4945, c. 951 e 964v.

Molto Illustre Signor mio osservantissimo,

Mi scrive di Lisbona Girolamo Cavalcanti d'Albuquerque, la cui casa e padre vivono nel Brasile, come V. A. vedrà dall'incluse lettere, che qui vanno per S. A. nostro Signore. Penso che costà dovrà esser noto questo ramo de'Cavalcanti trapiantato nell'India e si vede che la gloriosa memoria del Granduca, che sia in cielo, conosceva il padre del suddetto Girolamo. Pare che in quelle parti siano imparentati nobilmente, secondo che mi scrive e testifica la Sig.ra D.a Beatrice de Menezes e così non ho che dire $\mathrm{a} \mathrm{V}$. A. altro. se non rimettermi a quel che si contenga nelle suddette incluse lettere per S. A., e di nuovo bacio a V. S. le mani. Di Madrid a'27 di gennaio 1618.

Di V. S. molto illustre, servo obbligatissimo

\section{ORSO D'ELCI}

Al molto ill. signor mio osservandissimo il signor

Curzio Picchena

Segretario di Stato di S. A. S. FIRENZE. 